\title{
EFFECT OF EXTRUSION ON NUTRITIONAL COMPOSITION OF FEED CONTAINING MUSSEL MEAT: EXPERIMENTAL STUDY RESULTS
}

\author{
Viktor Pakhomov $^{1}$, Sergey Braginets ${ }^{1}$, Oleg Bakhchevnikov ${ }^{1}$, Dmitry Rudoy ${ }^{2}$ \\ ${ }^{1}$ Agricultural Research Centre Donskoy, Russia; ${ }^{2}$ Don State Technical University, Russia \\ vniptim@gmail.com, sbraginets@mail.ru,oleg-b@list.ru,dmiriyrudoy@gmail.com
}

\begin{abstract}
For the Baltic Sea countries edible mussel meat (Mytilus edulis L.) is a promising type of protein raw material for feed. The purpose of the study was to experimentally verify the possibility of feed mixture extrusion, including grain crops and mussel meat, and to determine rational parameters of the extrusion process. On a single screw extruder, at various temperatures, there was extruded a feed mixture containing ground wheat grain and mussel meat $(10,12.5$ and $15 \%$ by weight); and there was identified the amino acid percentage in the finished extrudate by capillary electrophoresis. According to the study results, it has been found that a feed mixture consisting of wheat grain and mussel meat could be successfully extruded at a temperature of 120$135^{\circ} \mathrm{C}$. Mussel meat added to wheat grain significantly increased the protein percentage in the finished feed. The increase of extrusion temperature resulted in a decrease of the amino acid percentage in the finished extrudate. The change of the mussel meat percentage in the feed mixture has virtually no effect on the dependence of the amino acid percentage in the extrudate on the extrusion temperature and the process. The amino acid percentage in the extruded feed at increasing temperature decreased with an accelerated velocity, regardless of mussel meat percentage in the feed mixture. A rational temperature range has been identified for feed mixture extrusion from wheat grain and mussel meat, it was $120-125^{\circ} \mathrm{C}$. The extrusion of mussel meat mixed with grain crops is considered to be a promising direction to improve the production of feed for fish and farm animals.
\end{abstract}

Keywords: feed, mussel meat, extrusion, extrudate, amino acids.

\section{Introduction}

Currently, it is important to improve the feed quality for farm animals and aquaculture that necessitates to ensure a high content of protein in them [1]. The presence of animal components with high protein percentage in the feed is of special importance, since they are necessary to satisfy the needs of animals in indispensable amino acids [2]. But in recent years, there has been a decrease in the production of feed components of animal origin, such as fish and krill meal, as they caused their cost increase [3].

All over the world there are being conducted researches to find new feed components with high protein percentage, including indispensable amino acids [4]. For the Baltic Sea countries edible mussel meat (Mytilus edulis L.) is a promising type of feed raw material due to its protein percentage [5] (Fig. 1a). The advantage of mussel meat as a feed component is the high protein percentage, $11-12 \%$ (60$65 \%$ of dry matter), while the proportion of digestible protein is $70-80 \%$ [6]. The fat is of $2-3 \%$ [7]. Mussel meat moisture content is very high, 80-82 \% [6; 7].

The disadvantage of mussels as feed raw material is their high cost. But this drawback can be overcome by processing small and sub-standard mussels for feed production [8].

To include mussel meat in the combined feed, it is essential to be pre-processed by separating shells and reducing moisture. The easiest way to reduce moisture is to use convective drying of meat at a temperature of $80-85^{\circ} \mathrm{C}$. The disadvantage of this method is the partial denaturation of protein under long heating. Nevertheless, mussel meat is subjected to convective drying and fine grinding to obtain dried mass, which is an analogue of fish meal, which contains $60-65 \%$ of protein, $70-75 \%$ of which is digestible, and 5-8\% of fat [9]. It has been established that the amino acid profile of mussel meal was similar to the profile of fish meal [10].

The inclusion of mussel meat in the combined feed in the form of meal requires preliminary expensive processing. The best option for the cost would be inclusion of meat into the feed without preliminary processing or with minimal processing.

The authors of the current paper have proposed a method of mussel meat inclusion into feed for farm animals and fish, which is its mutual extrusion with grain crops, winter wheat in particular. The grain of wheat, barley and other grain crops has a small percentage of protein, especially indispensable amino acids. Mussel meat added to it would increase the protein percentage in feed. But when introducing raw materials with protein in the feed mixture, there should be taken into account a possibility of their partial denaturation during extrusion. 
Extrusion of feed raw material due to the high energy consumption of this process was an expensive operation. But if the technological scheme of feed production is provided for extrusion of all components or a part of them, 10-15\% of mussel meat added to them would not result in a significant cost increase of finished feed, and the cost of mussels' processing would be low.

For qualitative grain extrusion it was necessary to moisten it that increased the cost of feed preparation [11]. The alternative method were to add other raw materials with high moisture content to grain and to extrude them jointly, which reduced the energy consumption of the process. Mussel meat has got high moisture content of 80-82 \%, which allowed reducing the cost of preparing extruded feed to a minimum due to the rejection of its moistening.

The purpose of the current study was to experimentally verify the possibility of feed mixture extrusion, containing grain crops and mussel meat, and to determine rational parameters of the extrusion process, which would ensure preservation of a high protein percentage in the extruded feed.

\section{Materials and methods}

Mussel meat and winter wheat grain were used as raw materials for extrusion. Mussels were grown in the Black Sea on the farm located near Gelendzhik and were delivered alive in a container. Before use, the mussels were cleaned of shells. The mussel meat was blanched for 2 minutes to disinfect and reduce moisture. The moisture content of the processed mussel meat was $45-50 \%$.

Winter wheat grain was used harvested in 2019, grown in the Rostov region of Russia. The grain was crushed on a hammer mill with a sieve with perforation of $3 \mathrm{~mm}$ diameter. The moisture content of the grain was $12-14 \%$.

To prepare extruded feed, a single-screw extruder was used, designed and manufactured at the Agricultural Research Centre Donskoy (Fig. 1a).

a)

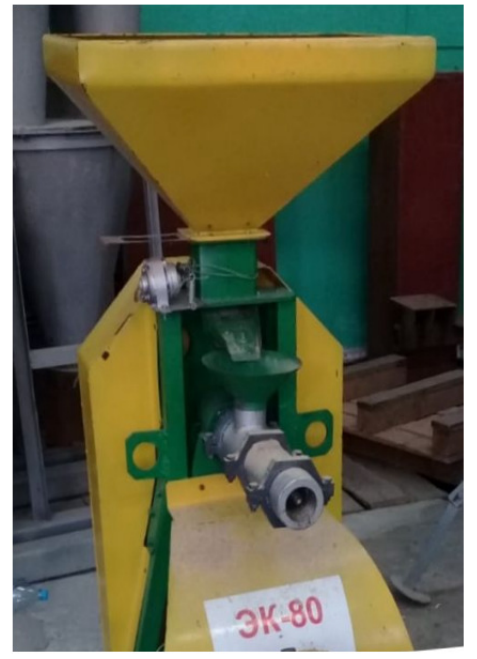

b)

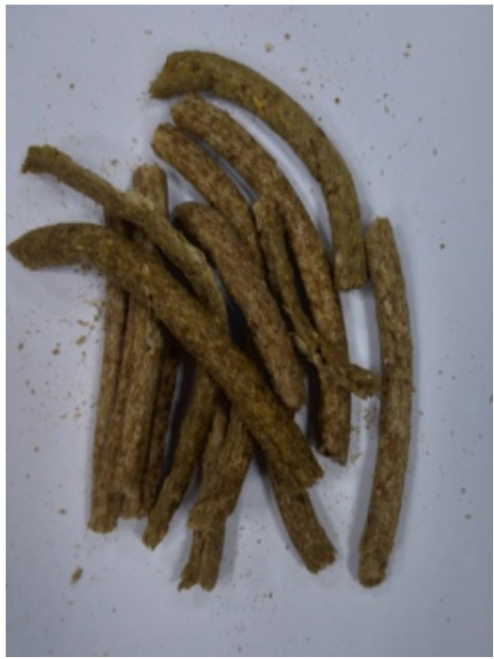

Fig. 1. Experimental single screw extruder (a) and extruded feed obtained from wheat grain and mussel meat (b)

The maximum productivity of the extruder was $80 \mathrm{~kg} / \mathrm{h}$, the electric motor power was $7.5 \mathrm{~kW}$. The rotational speed of the extruder screw was $220-308 \mathrm{~s}^{-1}$. The ratio of the screw length to its diameter was $L / D=6: 1$ when $D=55 \mathrm{~mm}$. The diameter of the outlet hole of the draw die was $10 \mathrm{~mm}$.

The ground wheat grain and mussel meat were pre-mixed in a household mixer. The resulting mixture was manually placed into the extruder and extruded. The extrudate strand leaving the draw die of the extruder was chopped with a rotating knife, resulting in granules of about $100 \mathrm{~mm}$ in length (Fig. 1b). The obtained granules were cooled to room temperature by natural cooling. Then the granules were packed in plastic bags and sent for analysis.

There were 3 extruded variants of the feed mixture with different compositions. Variant 1 contained mussel meat + wheat grain in a ratio of 10:90 (by weight). Variant 2 consisted of mussel meat + wheat grain in a ratio of 12.5:87.5. Variant 3 included mussel meat + wheat grain in the ratio of $15: 85$. 
For comparison, there was extruded feed containing only ground wheat grain (a control sample). Extrusion of the control sample was carried out at a screw speed of $220 \mathrm{c}^{-1}$, the temperature of the extrudate leaving the matrix was $124^{\circ} \mathrm{C}$.

Extrusion of each variant of the mixture was conducted at a rotational speed of the extruder screw 220-308 $\mathrm{c}^{-1}$. The screw rotational speed was changed by a frequency converter. The temperature of the extrudate leaving the extruder matrix was measured with a thermocouple.

Each variant of the mixture was prepared in an amount of $200 \mathrm{~g}$. The experiment on the extrusion of each variant of the mixture was carried out in three sequences. The extrudate samples were subjected to chemical analysis by the standard methods, determining the total protein percentage, as well as the moisture. The diameter of the extrudate granules to determine its expansion index was measured with a caliper.

The percentage of various amino acids in the extrudates was estimated by capillary electrophoresis in sufficient detail [12]. The samples were studied in the experimental laboratory of "Biochemical and spectral analysis of food products" of the Don State Technical University. The method of capillary electrophoresis was in the decomposition of extrudate samples by acid hydrolysis, which caused the transition of amino acids into free forms, and their electrophoretic separation [12]. Electrophoretic separation of amino acids was carried out using a phosphate buffer solution. The quantity of the various amino acids percentage was estimated by the electrophoregram analysis. The amino acid percentage was identified at a wavelength of $254 \mathrm{~nm}$. The tryptophan percentage was assessed by the recording method of absorption at a wavelength of $219 \mathrm{~nm}$. The total amount of aspartic acid and asparagine, glutamic acid and glutamine, as well as leucine and isoleucine was identified without their separation.

When analyzing the experimental results, the effect of the extrusion temperature and the mussel meat percentage in the feed mixture on the amino acid percentage in the finished extruded feed was estimated. The total percentage of amino acids in the extrudate and the indispensable amino acid percentage (arginine, valine, histidine, leucine, lysine, methionine, threonine, tryptophan, phenylalanine) were used as an indicator of the extruded feed quality.

The results of measurements are presented in the form: mean value \pm root-mean-square deviation. Reliability of averages distinctions was determined by the method of single-factor analysis of variance, using the a posteriori analysis by Tukey's range test in case of $p<0,05$.

\section{Results and discussion}

As the result of experiments, it has been found that a feed mixture consisting of ground grain crops, wheat in particular, and mussel meat could be successfully extruded in a single-screw extruder. The process of feed mixture extrusion proceeded satisfactorily at a temperature of $120-135^{\circ} \mathrm{C}$. At a temperature of less than $120^{\circ} \mathrm{C}$, the extrusion process proceeded inefficiently, which resulted in an extrudate of unsatisfactory quality with an inhomogeneous structure. At an extrusion temperature of more than $135{ }^{\circ} \mathrm{C}$, the extrudate was burnt slightly, resulting in a significant destruction of nutrients.

\section{Amino acid percentage of extruded feed obtained from wheat grain and mussel meat}

Table 1 (at a temperature of $124^{\circ} \mathrm{C}$ )

\begin{tabular}{|c|c|c|}
\hline $\begin{array}{c}\text { Variant of feed } \\
\text { mixture }\end{array}$ & $\begin{array}{c}\text { Total amino acid } \\
\text { percentage, } \%\end{array}$ & $\begin{array}{c}\text { Indispensable amino } \\
\text { acid percentage, \% }\end{array}$ \\
\hline 1 & $6.06 \pm 0.08$ & $2.11 \pm 0.06$ \\
\hline 2 & $7.05 \pm 0.08$ & $2.63 \pm 0.06$ \\
\hline 3 & $8.21 \pm 0.09$ & $3.33 \pm 0.07$ \\
\hline Control sample & $4.68 \pm 0.07$ & $1.55 \pm 0.04$ \\
\hline
\end{tabular}

The extrusion of a mixture of wheat grain and mussel meat at a temperature of $120-135{ }^{\circ} \mathrm{C}$ resulted in extruded fish feed of good quality. The finished extrudate had a homogeneous structure. The moisture content of the finished extrudate was 9.3-10.8\%, therefore there was no need for drying it. The diameter of the extrudate granules was $11.1-16.2 \mathrm{~mm}$, the extrudate expansion index was 1.11- 
1.62. The low extrudate expansion index was due to the mussels containing a large protein amount, added into the feed mixture.

It has been found that when from $10 \%$ to $15 \%$ of mussel meat (by weight) was added to the ground wheat grain, the total amino acid percentage in the finished extruded feed increased from $29 \%$ to $75 \%$, compared with the extrudate obtained from wheat grain (Table 1).

When adding from $10 \%$ to $15 \%$ of mussel meat (by weight), the indispensable amino acid percentage in the finished extrudate ranged from $36 \%$ to $115 \%$, compared to the extruded feed obtained only from wheat grain.

In Fig. 2 and 3 the graphs illustrate the dependence of amino acid percentage in the extruded feed on the extrusion temperature.

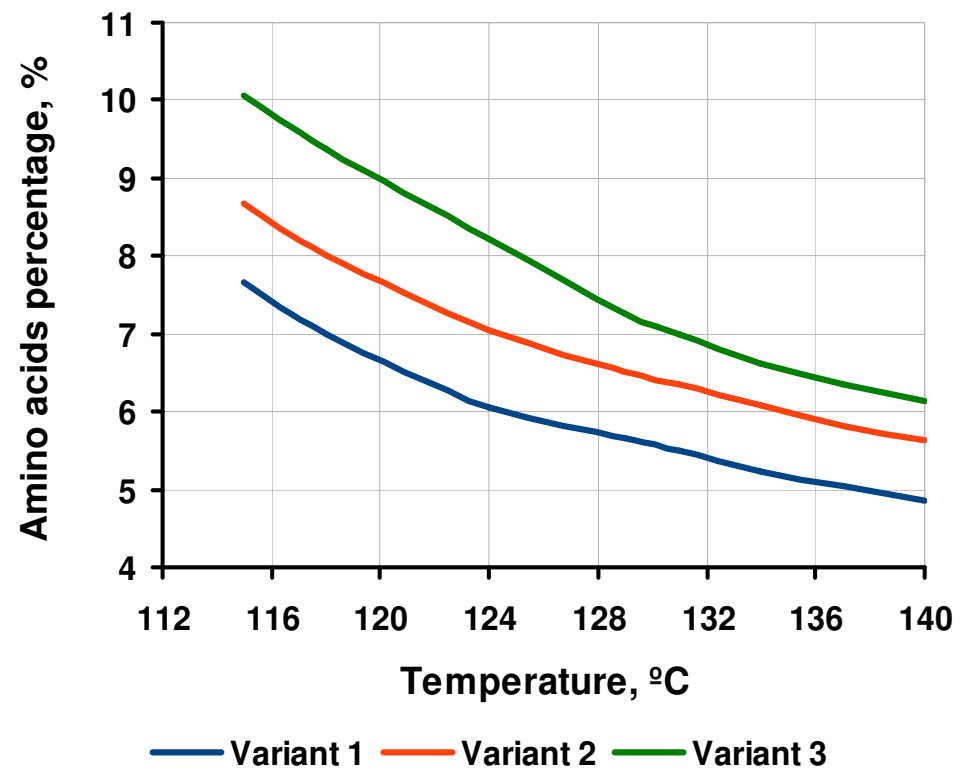

Fig. 2. Dependence of the total amino acid percentage in the extruded feed on the extrusion temperature

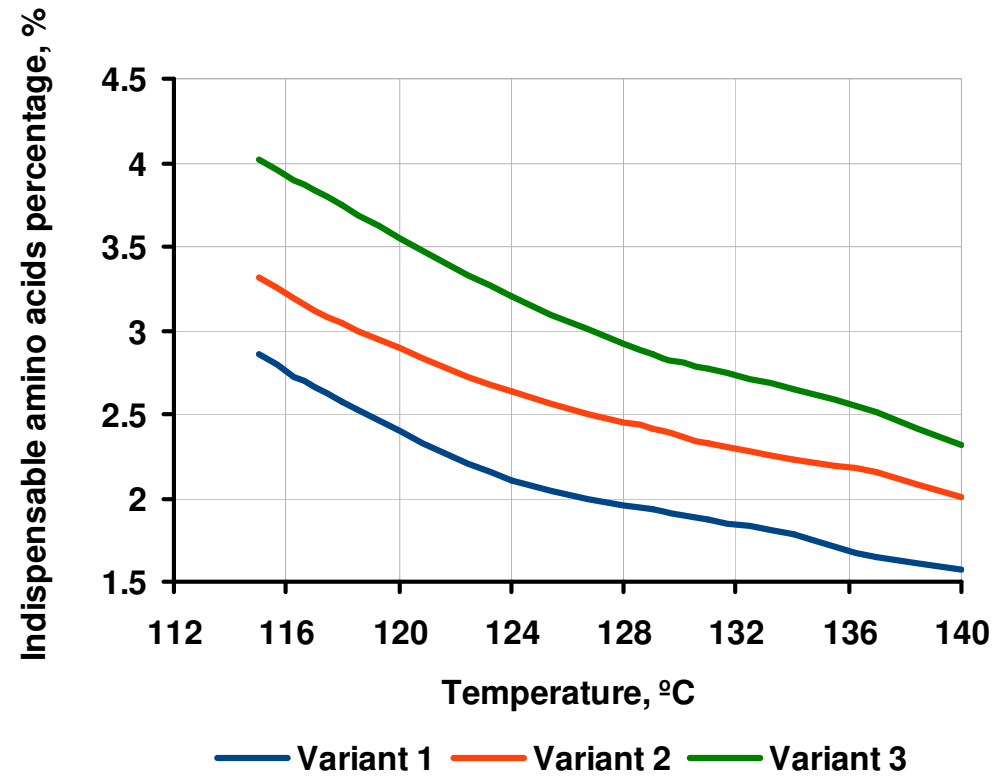

Fig. 3. Dependence of the indispensable amino acid percentage in the extruded feed on the extrusion temperature

It has been established that, when the extrusion temperature raised in the range of $115-138^{\circ} \mathrm{C}$, the amino acid percentage in the finished extrudate obtained from wheat grain and mussel meat decreased $(p<0.05)$. In particular, when extruding a feed mixture with $12.5 \%$ of mussel meat, the total amino 
acid percentage in the extrudate decreased from $8.69 \pm 0.09 \%$ at a temperature of $115{ }^{\circ} \mathrm{C}$ to $6.06 \pm 0.08 \%$ at a temperature of $138^{\circ} \mathrm{C}$, the indispensable amino acid percentage decreased from $3.21 \pm 0.04 \%$ at a temperature of $115^{\circ} \mathrm{C}$ to $2.25 \pm 0.04 \%$ at a temperature of $138^{\circ} \mathrm{C}$.

But even at the maximum temperature of $138^{\circ} \mathrm{C}$, the total amino acid percentage in the finished extrudate obtained from wheat grain and mussel meat was 10-38\% higher than in the extrudate obtained only from wheat grain. The percentage of indispensable amino acids in the extrudate made from the feed mixture at the maximum temperature of $138{ }^{\circ} \mathrm{C}$ was on $12-57 \%$ higher than in the extrudate made from wheat grain.

The amino acid percentage in the feed during extrusion reduced under the effect of high temperature because of the destruction of the part of free amino acids or their reaction with sugars that resulted in the formation of protein-carbohydrate complexes.

The analysis of the experimental results has found no differences between the nature of the change in the total amino acid percentage (Fig. 2) and the indispensable amino acid percentage (Fig. 3) in the extrudate under extrusion temperature increase $(p>0,05)$. The obtained graphs have shown that a change in the mussel meat percentage in the feed mixture had virtually no effect on the dependence of the amino acid percentage in the extrudate upon the extrusion temperature.

Fig. 4 presents a graph of the dependence of the indispensable amino acid percentage in the extruded feed on the extrusion temperature and the mussel meat percentage in the feed mixture.

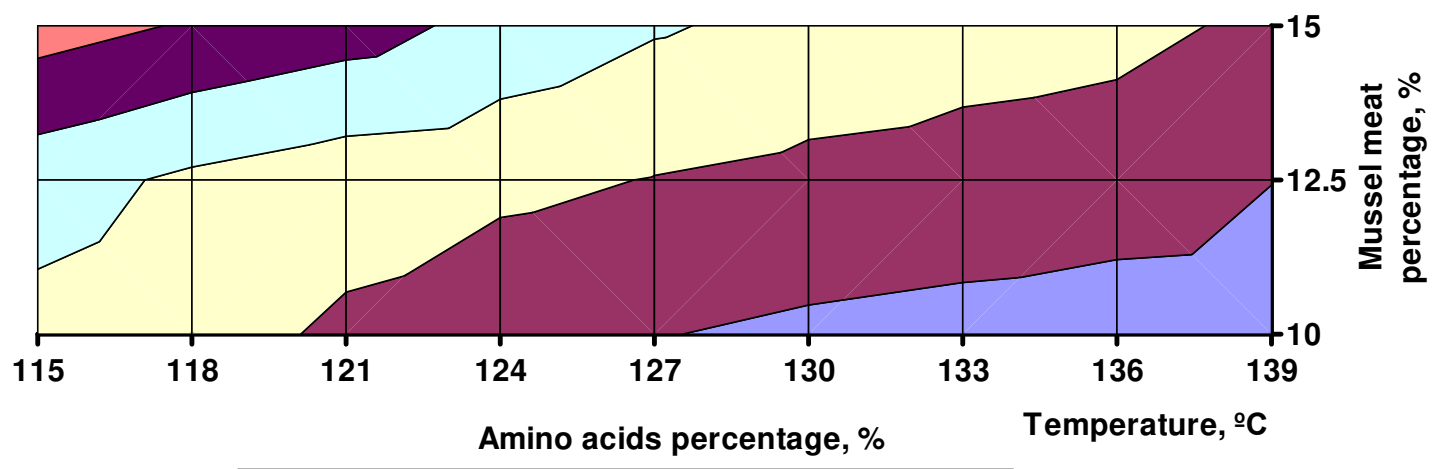

1.5-2 $\square$ 2-2.5 $\square$ 2.5-3 $\square$ 3-3.5 $\square$ 3.5-4 $\square$ 4-4.5

Fig. 4. Dependence of the indispensable amino acid percentage in the extruded feed upon the extrusion temperature and mussel meat percentage in the feed mixture

This graph has also shown that the extrusion process did not depend a lot on the mussel meat percentage in the feed mixture; it was the extrusion temperature that had the main effect on it. The extrusion temperature increase reduced the total amino acid percentage and the indispensable amino acid percentage in the finished extrudate $(p<0,05)$.

Fig. 5 shows a graph of the instantaneous velocity of change in the indispensable amino acid percentage in the extrudate under the change of extrusion temperature. In this case, the instantaneous velocity has shown how the amino acid percentage in the extrudate changed when the extrusion temperature changed by one degree. The values of the instantaneous velocity of change in the amino acid percentage have been obtained from the equation, which is a derivative function of the change of amino acid percentage under temperature change (Fig. 3). The lines in Fig. 5 are the graphs of the derivative functions of the trend lines for graphs shown in Fig. 3.

It has been found that the instantaneous velocity of change in the indispensable amino acid percentage in the extrudate linearly increased under the extrusion temperature increase. In particular, when extruding a feed mixture with $12.5 \%$ of mussel meat, the instantaneous velocity of change in the indispensable amino acid percentage increased from $0.043 \% \cdot{ }^{\circ} \mathrm{C}^{-1}$ at a temperature of $115^{\circ} \mathrm{C}$ to $0.188 \% \cdot{ }^{\circ} \mathrm{C}^{-1}$ at a temperature of $139{ }^{\circ} \mathrm{C}$. Thus, the amino acid percentage in the extruded feed reduced with an ascending speed when the temperature increased.

The graph analysis in Fig. 5 has shown that, when the mussel meat percentage in the feed mixture increased, the instantaneous velocity of change in the amino acid percentage increased slightly. 


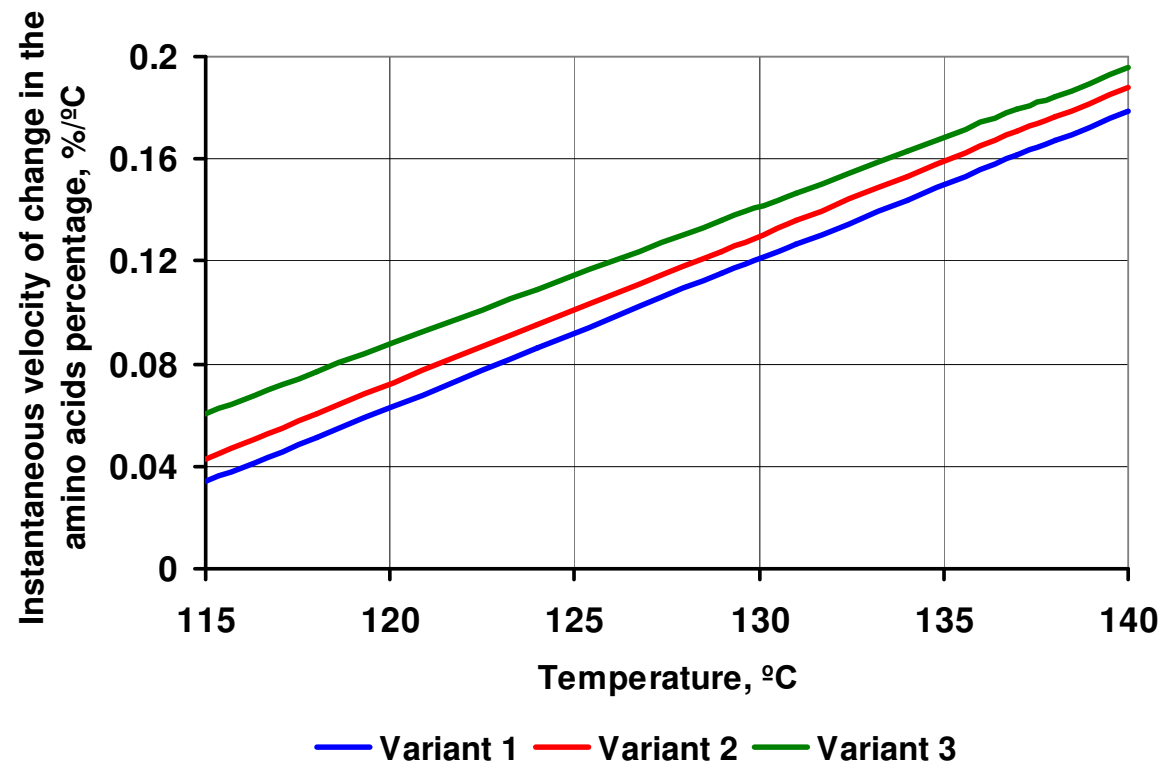

\section{Fig. 5. Graph of the instantaneous velocity of change in the indispensable amino acid percentage in the extrudate under the change of extrusion temperature}

Thus, when the mussel meat percentage in the feed mixture increased from $10 \%$ to $12.5 \%$, the instantaneous velocity of change in the amino acid percentage increased only $0.01-0.012 \%$. Moreover, the change in the mussel meat percentage in the feed mixture has had almost no effect on the dependence of the instantaneous velocity of change in the amino acid percentage upon the extrusion temperature.

The analysis of the experimental results has shown that there were no factors limiting the opportunity to extrusion efficiently a feed mixture from wheat grain and mussel meat, if the mussel meat percentage was up to $15 \%$, and possibly more.

The analysis of the graphs presented in Fig. 2-5 has shown that the change in the amino acid percentage in the extrudate and the instantaneous velocity of change in the amino acid percentage in the extrudate mainly depended on the extrusion temperature. These parameters were little dependent on the mussel meat percentage in the feed mixture.

The efficiency of the feed mixture extrusion from wheat grain and mussel meat depended on the extrusion temperature. A satisfactory extrudate could be obtained at an extrusion temperature of $120{ }^{\circ} \mathrm{C}$ to $135^{\circ} \mathrm{C}$. But the temperature increase reduced the amino acid percentage in the finished extrudate. Therefore, it was necessary to identify the rational temperature range of feed mixture extrusion, at which the extrusion proceeded satisfactorily, but there was no significant decrease in the amino acid percentage in the extrudate.

Based on the analysis of the experimental data, a rational temperature range for feed mixture extrusion from wheat grain and mussel meat has been identified, it was $120-125^{\circ} \mathrm{C}$. This temperature range has been identified for the feed mixture with $15 \%$ (by weight) of mussel meat. Based on the experimental data (Fig. 2-5), it could be assumed that the range of $120-125^{\circ} \mathrm{C}$ was also rational for feed mixture extrusion with a high percentage of mussel meat.

\section{Conclusions}

1. The conducted experimental study has found that the feed mixture consisting of ground grain crops and mussel meat (about 10-15\% by weight) could be successfully extruded at a temperature of $120-135^{\circ} \mathrm{C}$. Mussel meat added to grain significantly increased the protein percentage, including indispensable amino acids, in the finished extruded feed.

2. It has been identified that the extrusion temperature increase in the range of $115-138^{\circ} \mathrm{C}$ reduced the amino acid percentage in the finished extrudate obtained from wheat grain and mussel meat. But even at the maximum temperature of $138{ }^{\circ} \mathrm{C}$, the total amino acid percentage in the finished 
extrudate obtained from wheat grain and mussel meat was 10-38\% higher than in the extrudate obtained only from wheat grain.

3. The change in the mussel meat percentage in the feed mixture has had virtually no effect on the nature of the dependence of the amino acid percentage in the extrudate on the extrusion temperature and the course of the process.

4. It has been found that the amino acid percentage in the extruded feed quickly reduced when the temperature increased, regardless of the mussel meat percentage in the feed mixture.

5. Based on the analysis of the experimental data, a rational temperature range for feed mixture extrusion from wheat grain and mussel meat has been identified, it was $120-125^{\circ} \mathrm{C}$ that provided a slight decrease in the amino acid percentage in the extrudate.

6. Extrusion of mussel meat mixed with grain crops is considered to be a promising direction to improve the production of feed for fish and farm animals.

\section{References}

[1] Kim S.W., Less J.F., Wang L., Yan T., Kiron V., Kaushik S.J., Lei X.G. Meeting global feed protein demand: challenge, opportunity, and strategy. Annual Review of Animal Biosciences, 2019, vol. 7, No 1, pp. 221-243.

[2] Ayadi F.Y., Rosentrater K.A., Muthukumarappan K. Alternative protein sources for aquaculture feeds. Journal of Aquaculture Feed Science and Nutrition, 2012, vol. 4, No 1, pp 1-26.

[3] Olsen R.L., Hasan M.R. A limited supply of fishmeal: Impact on future increases in global aquaculture production. Trends in Food Science \& Technology, 2012, vol. 27, No 2, pp. 120-128.

[4] Carlberg H., Lundh T., Cheng K., Pickova J., Langton M., Gutierrez J.L.V., Kiessling A., Brannas E. In search for protein sources: Evaluating an alternative to the traditional fish feed for Arctic charr (Salvelinus alpinus L.). Aquaculture, 2018, vol. 486, pp. 253-260.

[5] Suplicy F.M. A review of the multiple benefits of mussel farming. Reviews in Aquaculture, 2018, pp. 1-20.

[6] Cui X. Baltic blue mussel (Mytilus edulis L.) and black soldier fly (Hermetia illucens) combined with pea protein concentrate as protein sources in feed for rainbow trout (Oncorhynchus mykiss). Uppsala, 2019. $33 \mathrm{p}$.

[7] Vidakovic A. Fungal and mussel protein sources in fish feed. Uppsala, 2019. 79 p.

[8] Arnason J., Bjornsdottir R., Larsen B.K., Thrandur Bjornsson B., Sundell K., Hansen A.C., Holen E., Espe M., Lindahl O., Kalsdottir S. Local fish feed ingredients for competitive and sustainable production of high-quality aquaculture feed LIFF. Oslo: Nordic innovation, 2015. $72 \mathrm{p}$.

[9] Afrose S., Hammershoj M., Norgaard J.V., Engberg R.M., Steenfeldt S. Influence of blue mussel (Mytilus edulis) and starfish (Asterias rubens) meals on production performance, egg quality and apparent total tract digestibility of nutrients of laying hens. Animal Feed Science and Technology, 2016, vol. 213, pp. 108-117.

[10] Jonsson L., Elwinger K. Mussel meal as a replacement for fish meal in feeds for organic poultry a pilot short-term study. Acta Agriculturæ Scandinavica. Section A, Animal Science, 2009, vol. 59, No 1, pp. 22-27.

[11] Irungu F.G., Mutungi C., Faraj A., Affognon H., Ekesi S., Nakimbugwe D., Fiaboe K.K. Optimization of extruder cooking conditions for the manufacture of fish feeds using response surface methodology. Journal of Food Process Engineering, 2018, vol. 42, No 2, pp. e12980.

[12] Desiderio C. Capillary electrophoresis - mass spectrometry for the analysis of amino acids. Journal of Separation Science, 2010, vol. 33, No 16, pp. 2385-2393. 